\title{
Clinico-pathological profile of Bone Metastases - A Single Institutional Study
}

\author{
Authors \\ Padhi Sanjukta ${ }^{1}$, Meher Papuji ${ }^{2}$, Sahoo Bijayalaxmi ${ }^{3}$, Patra Jitendra ${ }^{4}$, \\ Mahapatra Bikash Ranjan ${ }^{5}$
}

${ }^{1} \mathrm{MD}$, Associate Professor, Department of Radiation Oncology, A.H.Regional Cancer Centre, Cuttack

2,3,4,5 MD, Junior Resident, Department of Radiation Oncology, A.H.Regional Cancer Centre, Cuttack

Corresponding Author

Dr Sanjukta Padhi

Pithapur, Cuttack, Orissa

Email: drsanjuktapadhi@gmail.com,Tel \# 9437283032

\section{ABSTRACT}

Background: Cancer of head and neck, prostate and, lungs in males, cancer breast, cervix in females are the most common malignancies in India. These are also the leading cause of death. Patients often present with painful bone metastases. It is of a major concern to patients as well as oncologists.

Aim: To study different primary cancers giving rise to bone metastases. Age distribution, clinical profile, sites, patterns, \& distribution of occurrence, diagnostic methods, modes of management given are taken into account.

Materials: The treatment records of 227 patients of bone metastases undergoing palliative radiotherapy treatment at AHRCC. From January 2015 to December 2016 were retrieved and analysed retrospectively.

Results: Majority of patients were from 4th to 6th decade of life. Cancer prostate followed by lung cancer are most common in males. Breast and gynaecological cancer are common in females. Spine is the most favoured site followed by pelvis. Rib, long bone and skull metastases were also seen. Most of the patients presented with bony pain .All were managed with radiotherapy using different fractionation schedules. Few had undergone surgical interventions.

Conclusion: Skeletal metastases if properly managed can give rise to better quality of life. It depends upon the early and accurate diagnosis proper bone health maintenance and management by multidisciplinary team.

Keywords: Bone Metastases, radiotherapy.

\section{INTRODUCTION}

Breast cancer and Lung cancer are leading cancers in females and males respectively ${ }^{(1)}$. It continues to be the leading cause of cancer deaths in males and females. In the recent scenario bone metastases is a major concern for the oncologist as the incidence is increasing and if appropriate measure taken it can be prevented and managed to a great extent. Any malignancy can spread to bones but breast cancer, lung cancer and carcinoma prostate predominates in this arena. ${ }^{(2,3)}$

Majority of bone metastases occur in vertebrae and long bones but other sites can be less affected. Because it cause excruciating pain and bone fracture the general condition and quality of life deteriorates. $^{(3)}$ 
The aim of this study was to study age and sex distribution, clinical profile primary disease and spread pattern, treatment schedules and their response in patients having painful bone metastases.

\section{MATERIALS AND METHODS}

A total 227 cases were detected with bone metastases, data of patients were retrieved from treatment records from radiotherapy department of AHRCC a tertiary cancer centre from January 2015 -December 2016. All cases were histopathological proven primaries and later had painful bone secondaries, majority cases undergone cytological or core biopsy but all have done skeletal survey and bone scans. All had undergone palliative radiation and supportive care and bone stabilising agents. We analysed the clinico pathological profile, pattern of metastases by clinic-radiologic tool. Different fractionation radiation schedules were used to treat the metastatic sites.

\section{RESULTS}

From the data analysis total 227 bone secondaries cases identified in two years period, $53.74 \%$ were males and $46.26 \%$ were females. Out of 122 male patients 41 had prostate cancer, 23 had lung carcinoma,13 had gastrointestinal cancer,11 had carcinoma of unknown origin(cup)In 105 females breast predominates 51 cases, follwed by 16 gynaecological malignancy and 13 lung caricinoma. 7 had gastrointestinal malignancy. Metastases is more prevalent in the 40-59 year age group. Although it occurred in 5 cases below 20 year age group. (Table 1).

Spine is the most preferred site (77.53\%) contributed by breast, lung, prostate and cervical cancer .Pelvis is the next commonly affected site followed by long bones sternum, skull, scapula and ribs. (table-2). Most of the cases multiple sites involved. All were managed by giving palliative radiotherapy in three fractionation schedules. 30 grey in 10 sittings, 20 grey in 5 sitting and 8 grey in singe sitting (table-3).The number of fractions purely tailor made. Good general condition patients given 10 , followed by 5 and single as general condition deteriorates Out of all spines thoracic and lumber spines are mostly affected. (table-4)

Orthopaedic intervention done in 28 cases. All cases were given palliative care and counselling done by palliative care nursing personnel.

Table:1 Showing age group distribution

\begin{tabular}{ccc}
\hline Age Group(in years) & Number of cases & Percent value (\%) \\
\hline$<\mathbf{2 0}$ & 5 & 0.02 \\
$\mathbf{2 0 - 3 9}$ & 27 & 11.89 \\
$\mathbf{4 0 - 5 9}$ & 129 & 56.82 \\
$\mathbf{6 0 - 7 9}$ & 62 & 27.31 \\
$>\mathbf{8 0}$ & 4 & 0.01 \\
\hline
\end{tabular}

Table-2: Showing anatomical distribution of various primary sites

\begin{tabular}{|c|c|c|c|c|c|c|c|c|c|}
\hline Primary & Spine & Pelvis & Ribs & Sternum & Scapula & Skull & Humerus & $\begin{array}{c}\text { Tibia \& } \\
\text { Fibula }\end{array}$ & $\begin{array}{c}\text { Radius \& } \\
\text { Ulna }\end{array}$ \\
\hline $\begin{array}{c}\text { Breast } \\
\text { (51 Cases) }\end{array}$ & 41 & 19 & 0 & 12 & 3 & 5 & 20 & 3 \\
\hline $\begin{array}{c}\text { Lungs } \\
\text { (36 Cases) }\end{array}$ & 32 & 7 & 4 & 2 & 1 & 2 & 3 & 0 \\
\hline $\begin{array}{c}\text { Prostate } \\
\text { (41 Cases) }\end{array}$ & 29 & 4 & 1 & 2 & 3 & 1 & 6 & 1 \\
\hline $\begin{array}{c}\text { Gynecological } \\
(16 \text { Cases) }\end{array}$ & 14 & 3 & 0 & 0 & 0 & 0 & 0 & 0 \\
\hline $\begin{array}{c}\text { Git } \\
(20 \text { Cases })\end{array}$ & 10 & 9 & 1 & 0 & 0 & 0 & 3 & 0 \\
\hline
\end{tabular}


Table: 3: Showing various fractionation schedules used for palliative radiotherapy to bone

\begin{tabular}{cccc}
\hline $\begin{array}{c}\text { Total Dose(In } \\
\text { Gray) }\end{array}$ & $\begin{array}{c}\text { Dose Per Fraction } \\
\text { ( In Gray) }\end{array}$ & Total Fraction & Number \\
\hline $\mathbf{3 0}$ & 3 & 10 & $213(93.83 \%)$ \\
$\mathbf{2 0}$ & 5 & 4 & $10(4.4 \%)$ \\
$\mathbf{8}$ & 1 & 1 & $4(1.76 \%)$ \\
\hline
\end{tabular}

Table- 4: Showing distribution of anatomical subsites of spine among all spinal metastases

\begin{tabular}{cc}
\hline Spine Subsite & Total Number \\
\hline Cervical & 10 \\
Thoracic & 28 \\
Lumbar & 28 \\
Sacral & 2 \\
More Than 1 Subsite & 108 \\
\hline
\end{tabular}

\section{DISCUSSION}

THE BONE AND THE ONCOLOGIST NEWS UPDATES (BONUS) meeting is an annual Canadian multidisciplinary conference on the interaction of bone and cancer biology and concluded that cancer breast, prostate, thyroid, lungs and renal cancers are most common primaries ${ }^{(1,3)}$. In our case breast, prostate, lungs and gynaecological malignancies take the lead in bone metastasis.

Birsyn Yucel et al done a retrospective of data of 687 breast cancer patients and found 184 distant metastasis cases mostly in bone and lungs ${ }^{(4)} \mathrm{He}$ did a.mutivariate analysis on different factors done and seen that diabetic mellitus, positive lymphovascular invasion, high grade tumour biology are independent prognosticators. We found 51 cases of breast cancer cases with bone metastasis followed by gynaecological malignancies and then carcinoma lung. This figure of low lung cancer primaries and high gynaecological cancers probably is explained by low female smokers and high prevalence of gynaecological cancer in India.

Prostate cancer is though indolent in nature if not managed proper manner can have high propensity for bone metastases. Dainel P Petrylak reviewed the guidelines for health maintenance and Pub Med keyword search performed to identify risk factors of distant metastases. He reached in a conclusion that bone mineral density monitoring allow better preservation of skeletal health in patients undergoing ADT (androgen deprivation therapy). ${ }^{(5,6)}$
Bisphpshonates play a major role in preserving bone health.

Vahid Reza Dabbagh K et al did a study on 160 histologically proven consecutive cancer cases to find out correlation between pattern of bone scintigraphy with that of clinical data and concluded that spine and pelvis lesions significantly shown correlation with pain and scintigraphy. ${ }^{(2)}$ All our patients undergone skeletal survey and $73 \%$ done bone scintigraphy when complained pain or some skeletal related events (SRE). $27 \%$ non compliance to bone scan may be due to financial constrains of patients in a developing country. When clinical history and scintigraphy taken together the specificity increases. Radiotherapy and bone stabilising agents are the mainstay of treatment for painful bone metastases, It decreases pain to a great extent and kill the tumour cells at local sites ${ }^{(7,8)}$

\section{CONCLUSION}

No doubt from the above data analysis it hammers a collaborative relationship between clinical oncologist, urologist, radiation oncologists, radiologist, nuclear medicine specialist, orthopaedic surgeon, pallative care team to manage the skeletal metastasis cases in proper manner. The periodic screening of cancer survivors with or without bone pain is an emerging issue and needs to be addressed to avoid SRE related morbidity and mortality. The roles of general practitioners (gp) in identifying 
such cases become more vital in developing country like India.

Needless to mention here all is well as the quality of life improves in patients with bone metastasis if managed properly.

\section{Conflict of interest -Nil}

\section{REFERENCES}

1. Rebecca L. Siegel, ; Kimberly D. Miller,et al. Cancer Statistics 2016.Ca Cancer J clin 2016;66:7-30.

2. Vahid Reza Dabbagh Kakhki1, Kazem Anvari, Ramin Sadeghi1, et al Pattern and distribution of bone metastases in common malignant tumors Nuclear Medicine Review 2013, 16, 2: 66-69

3. Ricardo Fernandes, Peter Siegel, Svetlan Komarova et al.A Future directions for bone metastasis research highlights from the2015bone and theOncologist newupdates conference(BONUS) Journal of Bone Oncology 5(2016);57-62

4. Yücel B, Bahar S, Kaçan T, Şeker MM, Celasun MG,et al. Importance of Metastasis Site in Survival of Patients with Breast Cancer. Austin J Med Oncol. 2014;1(2): 7.

5. Daniel P. Petrylak. Risk Factors for The Development of Bone Metastases in Prostate Cancer europian urology s u p p l eme $\mathrm{n} \mathrm{t}$ s $6(20007) ; 677-682$

6. Doddala S, Suryadevara A, Chinta S, Madisetty A. Incidence and pattern of bone metastases at presentation in Indian carcinoma breast patients. Indian $\mathbf{J}$ Cancer2016;53:360-2.

7. Gillian Bedard, Edward Chow The failures and challenges of bone metastases research in radiation oncology Journal of Bone Oncology 2(2013):84-88
8. Sandra Casimiro, Arlindo R. Ferreira, André Mansinho et al, Molecular Mechanisms of Bone Metastasis: Which Targets Came from the Bench to the Bedside?, *Int. J. Mol. Sci. 2016, 17, 1415. 